\title{
Внешнее финансирование для переоснащения предприятия
}

\author{
Рассказывает генеральный директор AО «Эпиэл» Н. В.Тюрнев
}

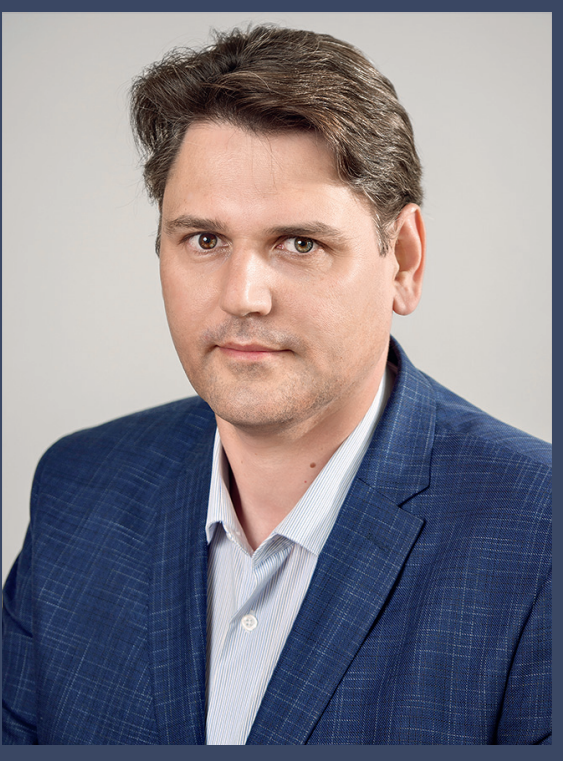

АО "Эпиэл" основано в августе 1998 года. Единственный

в России производитель, специализирующийся на выпуске кремниевых эпитаксиальных структур диаметром 76, 100, 150 и 200 мм. Уникальное современное инновационное производство позволяет более $70 \%$ продукции поставлять на экспорт: напрямую, либо косвенно - в составе конечного продукта. Более 50 предприятий радиоэлектроники по всей России являются потребителями продукции компании. Увеличение потребности в продукции предприятия и одновременно необходимость обеспечения высокого уровня ее конкурентоспособности заставили его искать источники финансирования с низкими процентными ставками. О том, как была решена эта задача, в данном интервью, продолжающем серию материалов про внешнее финансирование отраслевых компаний, рассказал генеральный директор АО "Эпиэл" Николай Валерьевич Тюрнев.

Николай Валерьевич, расскажите, пожалуйста, для чего потребовалось внешнее финансирование?

Перед предприятием стоит задача создания условий для импортозамещающих поставок эпитаксиальных структур на основе кремния российским приборостроителям электронной компонентной базы. Чтобы ее решить, потребовалось приобретение дополнительного технологического эпитаксиального оборудования, позволяющего выпускать продукцию диаметром до 200 мм под проектные нормы до 65 нм.

Наш уникальный для России проект имеет особое значение для отечественной электронной промышленности, так как закладывает прочный фундамент для ее дальнейшего развития. Кроме того, дополнительное оборудование позволяет увеличить производственную мощность предприятия, что требуется для удовлетворения растущего спроса на продукцию компании, в том числе со стороны экспортных заказчиков.

Общая сумма инвестиций для этого проекта составила 121,4 млн руб. Из них 50 млн руб. было обеспечено через привлечение займа у Московского фонда поддержки промышленности и предпринимательства.

Как вы узнали о возможности привлечь этот фонд?

Директор Московского фонда поддержки промышленности и предпринимательства (МФППиП) М. Ю. Лопухов проводил презентацию на одном из совещаний совета директоров, которые ежемесячно проводит Префектура зелАО. Нас заинтересовали возможности, которые фонд предоставляет производственным предприятиям.

Альтернативой являлись банковский кредит и лизинг, но финансовые условия предоставления данных видов финансирования были существенно хуже, чем предложил МФППиП. Среди ключевых преимуществ поддержки фонда - низкая процентная ставка и отсрочка выплаты основного долга.

\section{Были ли трудности при подготовке документов?}

Сложностей в подготовке документов практически не было, так как комплект документов очень похож на тот, которые обычно требуют банки. В случае МФППиП это было даже в какой-то степени проще.

Так как у нас достаточно большой опыт в использовании банковских кредитов, то весь комплект документов был подготовлен в течение 10 дней (с учетом времени получения необходимых справок в налоговой инспекции и т. п.).

Как скоро вы подписали договор с фондом и получили денежные средства?

Договор был подписан даже раньше, чем мы думали, в течение 2-х месяцев с момента принятия решения о работе с фондом. Это достаточно быстро - у нас был опыт 

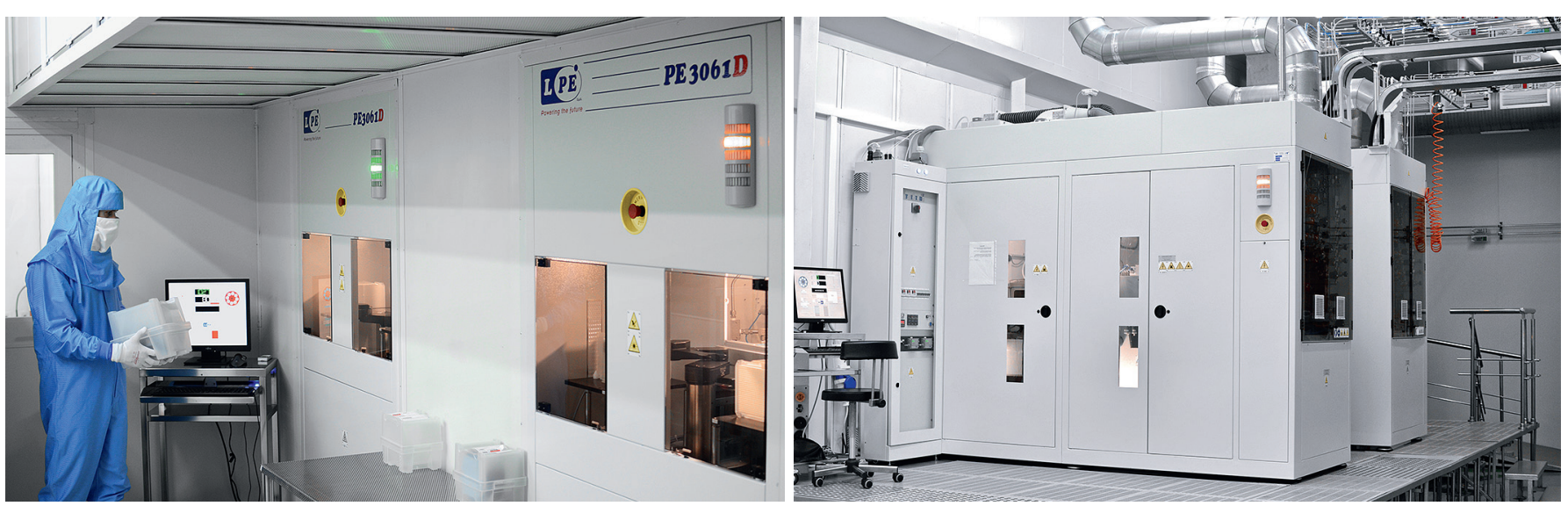

Эпитаксиальное оборудование: вид из "чистой" и "серой" зоны

с коммерческими банками, когда на рассмотрение и выдачу кредита обычно уходило 3-4 месяца, а в одном случае - даже девять (!) месяцев. Очевидно, что для бизнеса это неприемлемо. Задержек со стороны фонда практически не было. Перечисления средств проводились согласно графику Договора.

\section{Отчитываетесь фонду о выполнении проекта?}

Да, по формам фонда отчитываемся раз в квартал. В них отражаются основные события проекта (проведение оплат, поставка оборудования). В состав отчетности входит ежеквартальная стандартная финансовобухгалтерская отчетность компании.

\section{Какой срок реализации проекта, что даст предприя-} тию его выполнение?

Срок проекта - 5 лет (на самом деле 7 лет). В настоящий момент оборудование уже получено и выходит на свои проектные мощности.

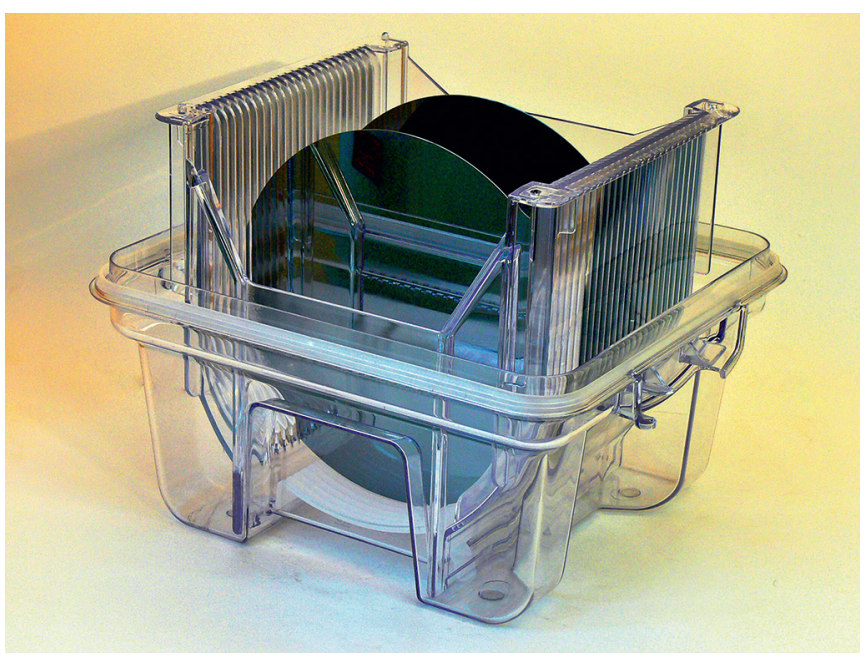

Кремниевые эпитаксиальные структуры диаметром 200 мм
В первую очередь проект увеличит возможности и мощности производства без увеличения количества сотрудников (115 человек) за счет увеличения производительности труда, что явится результатом использования в производстве приобретенного в рамках проекта самого современного оборудования.

А это значит, что мы в большей степени обеспечим потребности в первую очередь ведущих отечественных компаний в высокотехнологичных эпитаксиальных структурах диаметром 150 и 200 мм, а также получим возможность увеличить экспорт такой продукции .

Исполнение проекта позволит выпустить дополнительно продукции примерно на 100 млн руб. в год.

Будете ли обращаться еще в тот же фонд, и был ли раньше опыт работы с фондами?

Да, конечно, будем еще обращаться в МФППиП. Тем более, что с момента нашего первого обращения лимиты по выдаче займов у фонда увеличились в два раза: для аналогичного проекта они уже составляют не 50, а 100 млн руб. Хотя, в качестве пожелания, эти лимиты стоило бы увеличить еще в 2 раза - тогда их размер полностью соответствовал бы уровню стоимости закупаемого оборудования, и поддержка была бы более значимой.

У нас также был и продолжает накапливаться положительный опыт взаимодействия с фондом содействия кредитованию малого бизнеса Москвы. Этот фонд регулярно помогает гарантиями при получении банковских кредитов.

В целом отрадно констатировать, что возникают реальные механизмы государственной поддержки, которыми в том числе и удобно пользоваться.

\section{Спасибо за интересный рассказ.}

С Н. В. Тюрневым беседовала Н. А. Стецюк 